\title{
An Interrupted Time Series Analysis of COVID-19 Positivity before, during and after Lockdown in Four States of India
}

\author{
Shailaja Tetali ${ }^{1}$ (D), Guru Rajesh Jammy ${ }^{2}$ (D), Edwin Sam Asirvatham ${ }^{3}$ (1), \\ Bogam Ranjeeth Kumar ${ }^{4}$ (D), Lincoln Priyadarshi Choudhury ${ }^{*}$ (1)
}

\author{
${ }^{1}$ Public Health Foundation of India, Indian Institute of Public Health Plot No \# 1, ANV Arcade, Amar Co-op Society, \\ Hyderabad, India \\ ${ }^{2}$ Society for Health Allied Research and Education India (SHARE INDIA), MediCiti Institute of Medical Sciences Campus, \\ Medchal Telangana, India \\ ${ }^{3}$ Health Systems Research India Initiative (HSRII), Thiruvananthapuram, Kerala, India \\ ${ }^{4}$ Karshapana Consultants Private Limited Sri Sai Emerald Apt, Saidabad, Hyderabad, India \\ ${ }^{5}$ Karshapana Consultants private Limited U-151, DLF Capital Greens, Motinagar, New Delhi, India \\ Email: shailaja.t@iiphh.org, jammyrajesh@sharefoundations.org, aedwinsam@yahoo.com, ranjeethpaul01@gmail.com, \\ *lincolnchoudhury@gmail.com
}

How to cite this paper: Tetali, S., Jammy, G.R., Asirvatham, E.S., Kumar, B.R. and Choudhury, L.P. (2021) An Interrupted Time Series Analysis of COVID-19 Positivity before, during and after Lockdown in Four States of India. Open Journal of Epidemiology, 11, 47-55.

https://doi.org/10.4236/ojepi.2021.111005

Received: November 24, 2020

Accepted: January 2, 2021

Published: January 5, 2021

Copyright () 2021 by author(s) and Scientific Research Publishing Inc. This work is licensed under the Creative Commons Attribution International License (CC BY 4.0).

http://creativecommons.org/licenses/by/4.0/

\begin{abstract}
Objectives: The objective of this study was to examine the impact of large scale non-pharmaceutical interventions on COVID-19 pandemic. Methods: We used interrupted time series analysis (ITS), a quasi-experimental model to evaluate the effect of interventions in four states of India by comparing the COVID-19 positivity before lockdown, during lockdown and opening-up period. Results: The positivity in all the four states declined during lockdown and the trends reversed soon after the lockdown measures were relaxed as the states opened-up. The rate of reduction of positivity was significantly different between states. Between the lockdown and opening-up period, an increase in positivity was recorded in all the states with significant variation between states. Conclusion: The analysis provides conclusive evidence that the lockdown measures had a positive effect in reducing the burden of COVID-19 and establishes a causal relationship.
\end{abstract}

\section{Keywords}

Causality, Interrupted Time Series, COVID-19, Impact Evaluation

\section{Introduction}

India's first few cases of COVID-19 were detected in Kerala by the end of January 2020. The country's strategy till March, was to screen people with a history 
of international travel or contact with a known case of COVID-19, quarantine/isolate and treat. With a steady increase in the number of Influenza-Like Illness (ILIs) and Severe Acute Respiratory Infection (SARI) turning positive for COVID-19, the Government of India advised the States to invoke the provisions of Section 2 of the Epidemic Diseases Act 1897, to enable imposing restrictions like school and theatre closures, and banning large gatherings [1] [2]. The first large-scale containment measure in the form of a nationwide lockdown was introduced on March 25, till May 30, 2020 and later on, a phased unlock was introduced [3].

Mathematical models have widely been used to inform policy, programme planning, and service delivery related to COVID-19 [4]. Several models predicted the spread of COVID-19 with varying levels of accuracy [5] [6] [7]. These models forecasted the number and progression of infections and predicted the health system resource requirements, with different levels of assumptions about the effect of non-pharmaceutical interventions on the epidemic. Falxman et al., 2020, assumed an immediate effect on infectious people becoming less infective; $\mathrm{Da}$ vies et al., 2020, assumed a differential contact because of preferential self-isolation among people with clinical features; while Mandal et al., 2020, assumed the transmission dynamics in India to be similar to Japan and South Korea, considering half of the symptomatic cases to be quarantined within three days of developing symptoms [8] [9] [10]. These assumptions provided much-needed possible scenarios of epidemic forecasting, however, they did not offer conclusive evidence regarding non pharmaceutical interventions. Applying the principle of causality in measuring the effect of a policy intervention is crucial [11] [12] [13]. Our analysis examines the impact of lockdown as a policy intervention on COVID 19 positivity in four states of India.

\section{Methods}

\subsection{Data}

We obtained data on the number of tests and positive results for four states in India-Kerala, Tamil Nadu, Karnataka, and Odisha, from respective state governments' official COVID-19 dashboard or bulletin [14] [15] [16] [17]. These four states were selected as data was available consistently since the beginning of the epidemic.

Data was collected from March $15^{\text {th }}$ to the $3^{\text {rd }}$ week of July 2020 for all four states. This included the pre-lockdown period, lockdown period, and post-lockdown (opening up) period. The outcome of interest was daily test "positivity" (Test Positivity Rate-TPR) which is the number of reported positive tests of the total samples tested [18] [19]. We included three phases of time periods in the analysis:

Time series 1, Pre-lockdown period: $15^{\text {th }}$ March to $3^{\text {rd }}$ April was included in the analysis primarily to capture the early stage situation of the epidemic before lockdown. As we relied on positive test results published in the state bulletins, it was essential to capture those who got infected during pre-lockdown but were 
detected afterwards. To account for time-lags between infection during pre lockdown and obtaining test results, we added 10 days, considering an incubation period of 6 days and maximum delay to obtain test results as 4 days [20] [21].

Time series 2, Lockdown period 1 and 2: $4^{\text {th }}$ April to $9^{\text {th }}$ May reflects the lockdown period. Though the lockdown was lifted on $3^{\text {rd }}$ May, we considered 6 additional days to account for the spillover of the effect which is the difference between infection and reported test results. Six days was considered here, instead of 10 days, assuming increased efficiency of testing and reporting [22].

Time series 3, Relaxed lockdown to the Opening up period: 10th May to $19^{\text {th }}$ July consisted of gradual opening up phase.

Data pertaining to $22^{\text {nd }}$ March 2020 in Karnataka showed very high positivity (60\%), it was considered an outlier and excluded from analysis.

\subsection{Model}

We examined the impact of lockdown on the Test Positivity Rate (TPR). Though Randomised control trials (RCT) are considered the "Gold Standard" for impact evaluation, the pandemic nature of COVID-19 and population-level non-pharmaceutical interventions restrict the use of RCT in the current situation. We used interrupted time series analysis (ITS), a quasi-experimental model, which has been implemented elsewhere for other diseases including COVID-19 for evaluating the effect of population-level interventions over a period of time [23] [24] [25].

\subsection{Data Analysis}

A preliminary analysis was done using ordinary least squares (OLS) method. Autocorrelation function (ACF) and partial autocorrelation (PACF) function were used to examine the correlation of residuals of OLS in terms of moving average and autoregressive lags through the ACF and PACF plots. The final analysis was done using generalised least square model (GLS) to fit the data and appropriate lags indicated by the ACF and PACF plots for the respective states. The trend line for each time series was extended linearly to demonstrate the counterfactuals for the next time period i.e. for time series 2 and 3. The counterfactuals were used to examine the effect of time-varying policy interventions on the causality criteria of strength, consistency, specificity, temporality, plausibility, biological gradient, coherence, analogy, experimentation, and reversibility, with respect to Covid-19 positivity. Open-source software R was used for analysis [26].

\section{Results}

The TPR for all the states decreased in phase 2 (lockdown) and increased in phase 3 (Opening-up), even in states which had an initially high TPR, e.g.; Tamil Nadu's TPR was $13.1 \%, 4.0 \%$ and $9.6 \%$ during pre-lockdown, lockdown and 
opening up phase, while Karnataka's TPR was 3.4\%, $0.8 \%$ and $11.5 \%$ respectively.

Karnataka and Odisha had increasing trends in the TPR (solid blue line) during the pre-lockdown phase and predicted to increase (predicted direction is shown as broken blue line), if the lockdown had not been imposed (Figure 1 and Figure 4). The TPR decreased during phase 1 and 2 (solid red line) and would have presumably continued to decline (dashed red line, counterfactual). However, it rapidly increased during opening/post lockdown phase (solid light blue line). In contrast, the post lockdown TPR in Kerala and Tamil Nadu (Figure 2, Figure 3) increased slowly, as compared to the rapid increase in Karnataka and Odisha. During the opening up phase, the TPR showed a relatively slower increase in Tamil Nadu and Kerala and a steep increase in Odisha and Karnataka.

Other difference between the states included a steady increase in TPR in Odisha during opening up phase. Tamil Nadu's TPR increased till the end of March followed by a decline and continued to increase from early June. Karnataka showed a steep increase of around 3\% at the end of June, to $14 \%$ by the end of July. Kerala's TPR increased to almost $12 \%$ around the last week of March and reduced thereafter (Figures 1-4).

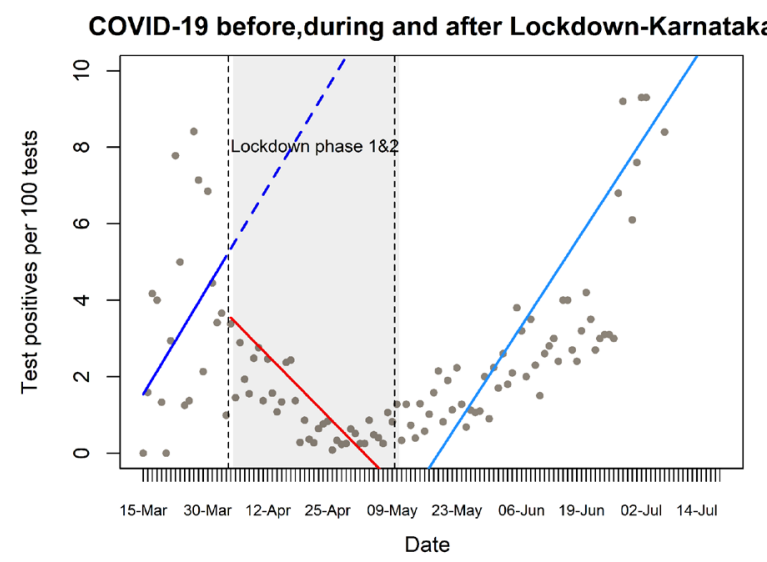

Figure 1. COVID-19 positivity in Karnataka.

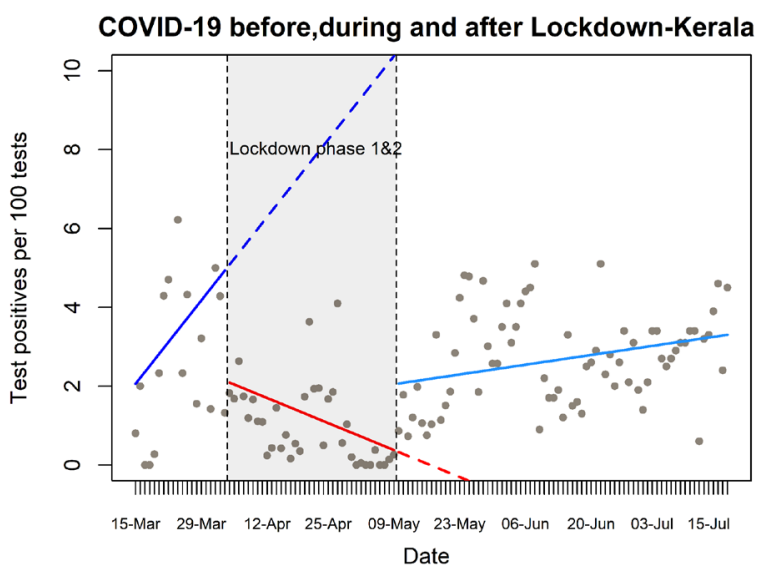

Figure 2. COVID-19 positivity in Kerala. 


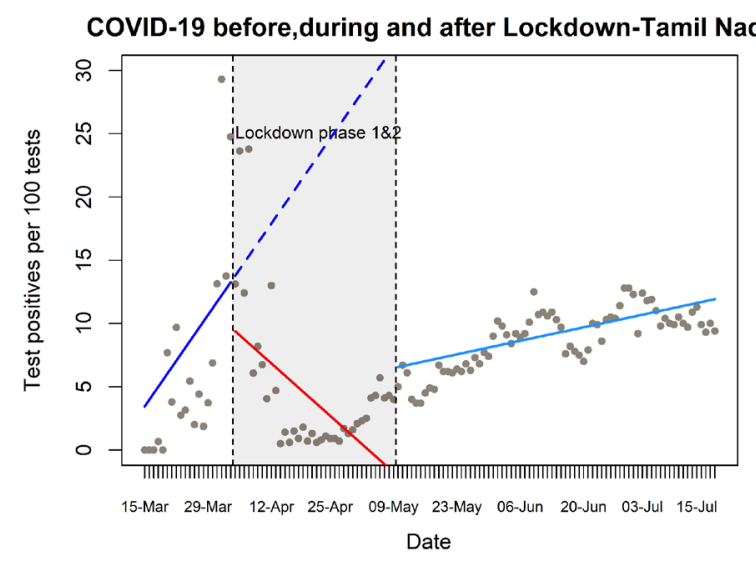

Figure 3. COVID-19 positivity in Tamil Nadu.

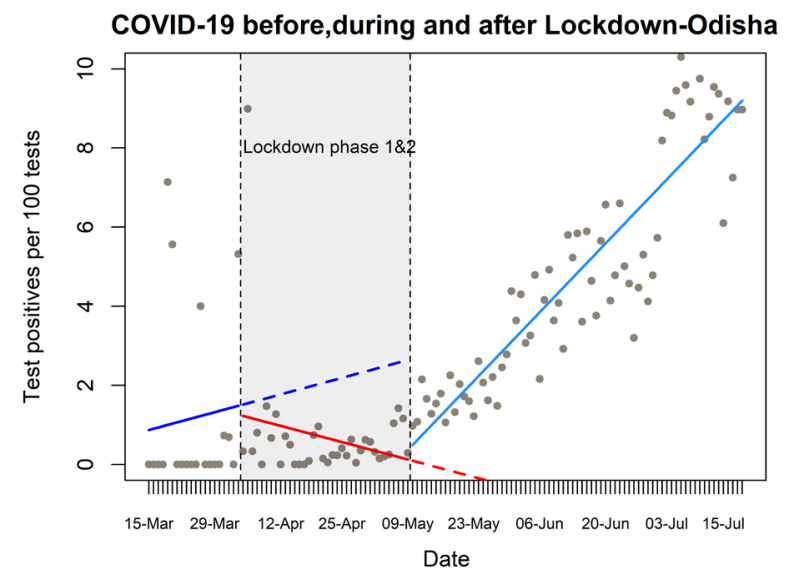

Figure 4. COVID-19 positivity in Odisha.

From pre-lockdown to lockdown period, there was a drop in TPR in all the states and the effect reversed during the unlock period except in Karnataka where the levels were lower during the relaxation of lockdown period. The lockdown resulted in statistically significant declining trends of TPR in all the states except Odisha. The declining trends reversed during opening up period, which were also statistically significant in all the states, except Kerala.

\section{Discussion}

Multiple non-pharmaceutical public health measures such as promotion of handwashing, usage of face masks, travel restrictions, contact tracing, isolation and treatment of cases were implemented concurrently, besides the national level lockdown. Our analysis indicated that the lockdown imposed in the country had a positive effect on the TPR of COVID-19 in all the four states. The counterfactual trends indicate that the TPR would have increased dramatically and substantiates the causal effect of a declining TPR brought by the lockdown. While the TPR increased during post lockdown and unlock period, it is evident that the lockdown had actually provided adequate time to prepare and strengthen the health systems by delaying the peak of infections, which could be the 
overall intent of policy makers and program planners.

The central question is the causal effect of lockdown on the pandemic and its direction. As demonstrated in Table 1, the reduction in the TPR during lockdown was statistically significant in all the states, except Odisha. During the unlock (opening up) period, the TPR increased significantly in all the states. It is essential to understand that test positivity depends on testing strategy, availability of test kits, sensitivity and specificity of test kits. As Indian Council of Medical Research (ICMR) suggested a uniform testing strategy for all states since the beginning of the epidemic, we assume the testing strategy to be consistent in the selected four states.

Before lockdown, large scale measures like international travel ban was implemented which did not fully prevent the spread of COVID-19 [27] and demonstrated the temporal relationship between lockdown and COVID-19 positivity. A few peaks in the epidemic had some reasons: For example, initial peaks in TPR in Kerala could be due to international returnees, and in Tamil Nadu, due to specific super spreader events causing isolated clusters early in the epidemic.

Table 1. Generalised least square regression results.

\begin{tabular}{|c|c|c|c|c|}
\hline State & Coefficients & Value & Std. Error & p-value \\
\hline \multicolumn{5}{|c|}{ Karnataka } \\
\hline & Lock-down level & -1.49 & 0.96 & 0.13 \\
\hline & Lock-down Trend & -0.32 & 0.16 & 0.04 \\
\hline & Open up Level & -1.11 & 0.79 & 0.16 \\
\hline & Open up Trend & 0.31 & 0.05 & 0.00 \\
\hline \multicolumn{5}{|l|}{ Kerala } \\
\hline & Lock-down Level & -2.79 & 1.13 & 0.01 \\
\hline & Lock-down Trend & -0.20 & 0.10 & 0.05 \\
\hline & Open up Level & 1.67 & 0.94 & 0.08 \\
\hline & Open up Trend & 0.07 & 0.04 & 0.13 \\
\hline \multicolumn{5}{|c|}{ Tamil Nadu } \\
\hline & Lock-down Level & -3.56 & 1.83 & 0.05 \\
\hline & Lock-down Trend & -0.84 & 0.15 & 0.00 \\
\hline & Open up Level & 8.25 & 0.66 & 0.00 \\
\hline & Open up Trend & 0.40 & 0.03 & 0.00 \\
\hline \multicolumn{5}{|l|}{ Odisha } \\
\hline & Lock-down Level & -0.22 & 1.06 & 0.83 \\
\hline & Lock-down Trend & -0.06 & 0.09 & 0.46 \\
\hline & Open up Level & 0.24 & 0.83 & 0.77 \\
\hline & Open up Trend & 0.16 & 0.04 & 0.00 \\
\hline
\end{tabular}


Essentially, the effect of lockdown is consistent with the general understanding that social distancing reduces the risk and spread of disease, as demonstrated in other disease models [28] [29].

\section{Conclusion}

The country-wide lockdown measures had a positive impact on COVID-19 response, indicated by reductions in daily positivity in four selected states in India. However, COVID-19 is a fluctuating and dynamic pandemic with too many varying operational and epidemiological factors that need to be considered while making interpretations. Further analysis at the district or regional level would be useful to inform local actions and undertake specific corrective measures.

\section{Acknowledgements}

This analytical work was not supported by any individual or organization and the authors did not receive any funding support for this work. The authors acknowledge the work of Prof Michael Law for sharing his codes in public domain and providing critical input.

\section{Conflicts of Interest}

The authors have no conflicts of interest associated with the material presented in this paper.

\section{Author Contributions}

Conceptualization: ST, GRJ, AEM, BRK, LPC, Data curation: ST, AEM, BRK, LPC. Formal analysis: GRJ, AEM, LPC. Methodology: ST, GRJ, AEM, BRK, LPC. Project administration: SKP. Visualization: LPC. Writing: ST, GRJ, AEM, LPC, Writing-review \& editing: ST, GRJ, AEM, BRK, LPC.

\section{References}

[1] Ministry of Home Affairs, Government of India (2020) Communication on Lockdown-Order. No: 40-3/2020-DM-I (A).

https://www.ndmindia.nic.in/images/gallery/MHA\%20order\%20(final).pdf

[2] National Disaster Management Authority (2020) Order Policy and Plan Division. https://ndma.gov.in/sites/default/files/PDF/covid/ndmaorder240320.pdf

[3] Ministry of Home Affairs, Government of India (2020) Order on Extension of Lockdown Measures, Order No: 40-3/2020-DM-I(A) 14th April 2020. https://www.ndmindia.nic.in/images/gallery/MHA\%20Order\%20dated\%2014.04.20 20.pdf

[4] Ivorra, B., Ferrández, M.R., Vela-Pérez, M. and Ramos, A.M. (2020) Mathematical Modeling of the Spread of the Coronavirus Disease 2019 (COVID-19) Taking into Account the Undetected Infections. The Case of China. Communications in Nonlinear Science and Numerical Simulation, 88, Article ID: 105303. https://doi.org/10.1016/j.cnsns.2020.105303

[5] Chandra, S.K., Singh, A. and Bajpai, M.K. (2020) Mathematical Model with Social Distancing Parameter for Early Estimation of COVID-19 Spread. MedRxiv. 
https://doi.org/10.1101/2020.04.30.20086611

[6] Prem, K., Liu, Y., Russell, T.W., Kucharski, A.J., Eggo, R.M., Davies, N., et al. (2020) The Effect of Control Strategies to Reduce Social Mixing on Outcomes of the COVID-19 Epidemic in Wuhan, China: A Modelling Study. The Lancet Public Health, 5, e261-e270. https://doi.org/10.1016/S2468-2667(20)30073-6

[7] Roosa, K., Lee, Y., Luo, R., Kirpich, A., Rothenberg, R., Hyman, J.M., et al. (2020) Short-Term Forecasts of the COVID-19 Epidemic in Guangdong and Zhejiang, China: February 13-23, 2020. Journal of Clinical Medicine, 9, 596. https://doi.org/10.3390/jcm9020596

[8] Flaxman, S., Mishra, S., Gandy, A., Unwin, H.J.T., Mellan, T.A., Coupland, H., et al. (2020) Estimating the Effects of Non-Pharmaceutical Interventions on COVID-19 in Europe. Nature, 584, 257-261. https://doi.org/10.1038/s41586-020-2405-7

[9] Davies, N.G., Kucharski, A.J., Eggo, R.M., Gimma, A., Edmunds, W.J., Jombart, T., et al. (2020) The Effects of Non-Pharmaceutical Interventions on COVID-19 Cases, Deaths, and Demand for Hospital Services in the UK: A Modelling Study. The Lancet Public Health, 5, e375-e385. https://doi.org/10.1016/S2468-2667(20)30133-X

[10] Mandal, S., Bhatnagar, T., Arinaminpathy, N., Agarwal, A., Chowdhury, A., Murhekar, M., et al. (2020) Prudent Public Health Intervention Strategies to Control the Coronavirus Disease 2019 Transmission in India: A Mathematical Model-Based Approach. Indian Journal of Medical Research, 151, 190-199. https://doi.org/10.4103/ijmr.IJMR $504 \quad 20$

[11] Hill, A.B. (1965) The Environment and Disease: Association or Causation? Journal of the Royal Society of Medicine, 58, 295-300. https://doi.org/10.1177/003591576505800503

[12] Gertler, P.J., Martinez, S., Premand, P., Rawlings, L.B. and Vermeersch, C.M.J. (2016) Impact Evaluation in Practice. 2nd Edition, Inter-American Development Bank and World Bank., Washington DC. http://dx.doi.org/10.1596/978-1-4648-0779-4

[13] Organisation for Economic Co-Operation and Development (2020) Evaluation Criteria-OECD.

https://www.oecd.org/dac/evaluation/daccriteriaforevaluatingdevelopmentassistanc e.htm

[14] Government of Kerala (2020) Kerala: COVID-19 Battle. https://dashboard.kerala.gov.in/

[15] Health Department Government of Odisha (2020) Detail Status of COVID-19. https://statedashboard.odisha.gov.in/

[16] Health \& Family Welfare Department Government of Tamil Nadu (2020) Daily Bulletin-StopCoronaTN. https://stopcorona.tn.gov.in/daily-bulletin/

[17] Health and Family Welfare Department, Government of Karnataka (2020) HomeCOVID-19 Information Portal. https://covid19.karnataka.gov.in/english

[18] Johns Hopkins University \& Medicine (2020) Track Testing Trends. Johns Hopkins Coronavirus Resource Center. https://coronavirus.jhu.edu/testing/tracker/overview

[19] World Health Organisation (2020) Malaria Test Positivity Rate (\%): The Global Health Observatory. https://www.who.int/data/gho/indicator-metadata-registry/imr-details/3151

[20] World Health Organisation (2020) Coronavirus Disease 2019 (COVID-19): Situation Report, 73. https://apps.who.int/iris/handle/10665/331686

[21] Hindustan Times (2020) City to Breach 3k Covid-19 Cases Today as Health De- 
partment Clears Backlog of Samples-Gurugram-Hindustan Times.

https://www.hindustantimes.com/gurugram/city-to-breach-3k-cases-today-as-healt h-department-clears-backlog-of-samples/story-7elmD6dyh1iYmiI8npnGVI.html

[22] The Times of India (2020) Coronavirus Symptoms: Almost 80\% of COVID Cases in India Asymptomatic: Union Health Minister.

https://imesofindia.indiatimes.com/life-style/health-fitness/health-news/almost-80of-covid-cases-in-india-asymptomatic-union-health-minister/articleshow/76069643 . $\mathrm{cms}$

[23] Kontopantelis, E., Doran, T., Springate, D.A., Buchan, I. and Reeves, D. (2015) Regression Based Quasi-Experimental Approach When Randomisation Is Not an Option: Interrupted Time Series Analysis. BMJ, 350, h2750.

https://doi.org/10.1136/bmj.h2750

[24] Medeiros De Figueiredo, A., Daponte Codina, A., Moreira, D.C., Figueiredo, M. Saez, M. and Cabrera León, A. (2020) Impact of Lockdown on COVID-19 Incidence and Mortality in China: An Interrupted Time Series Study. The Bulletin of World Health Organisation, 98, 150. https://doi.org/10.2471/BLT.20.251561

[25] Choudhury, L.P., Jammy, G.R. and Pant, R. (2020) Concurrent Impact Evaluation of Lockdown Measures on COVID-19 Positivity in Three States of India. International Journal of Community Medicine and Public Health, 7, 4028-4032. http://dx.doi.org/10.18203/2394-6040.ijcmph20204371

[26] R Core Team (2020) The R Project for Statistical Computing. https://www.r-project.org/

[27] Ministry of Health and Family Welfare (India) (2020) Consolidated Travel Advisory for Novel Coronavirus Disease (COVID-19). Ministry of Health and Family Welfare (India), New Delhi.

[28] Kucharski, A.J., Russell, T.W., Diamond, C., Liu, Y., Edmunds, J., Funk, S., et al. (2020) Early Dynamics of Transmission and Control of COVID-19: A Mathematical Modelling Study. The Lancet Infectious Diseases, 20, 553-558. https://doi.org/10.1016/S1473-3099(20)30144-4

[29] Jarvis, C.I., Van Zandvoort, K., Gimma, A., Prem, K., Auzenbergs, M., O’Reilly, K., et al. (2020) Quantifying the Impact of Physical Distance Measures on the Transmission of COVID-19 in the UK. BMC Medicine, 18, Article No. 124. https://doi.org/10.1186/s12916-020-01597-8 